\title{
O lugar da cultura nos Jogos Olímpicos: uma análise dos Jogos de Berlim (1936)
}

\author{
Culture's place in the Olympic Games: \\ an analysis of Berlin Games (1936)
}

\author{
Juliana da Silva Pinto Carneiro \\ Universidade Federal do Rio de Janeiro, Rio de Janeiro / Brasil \\ Doutoranda em História Comparada, UFRJ \\ julianaspcarneiro@gmail.com
}

REsumo: Este artigo pretende analisar a programação cultural e artística dos Jogos Olímpicos, a partir da compreensão que os programas de cultura são um campo privilegiado para a consolidação dos aspectos simbólicos presentes nas edições destes megaeventos. Na primeira parte do artigo as informações estão sistematizadas em um breve panorama temporal, estruturado a partir de três momentos: a) De 1896 a 1912: as artes e a cultura não estavam formalmente inseridas nos Jogos Olímpicos; b) De Estocolmo (1912) a Londres (1948): edições de Jogos Olímpicos com competições das artes olímpicas; c) De Melbourne (1956) a Barcelona (1992): as diferentes concepções de programação cultural. Na segunda parte, o artigo investiga mais detidamente os Jogos de Berlim (1936), partindo da premissa que o governo alemão entendeu a "força simbólica dos elementos culturais" e a potencializou com estratégias de propaganda para consolidar as principais representações do modelo nazista.

PalaVRas-chave: Programação Cultural; Jogos Olímpicos; Cultura; Jogos de Berlim.

ABSTRACT: This article intends to analyse the cultural and artistic programmes of the Olympic Games, from the comprehension which cultural programmes are a privileged pitch for the consolidation of this megaevents' symbolic aspects. In the first part of the article the information is ordered in a brief time overview, from three moments: a) from 1896 to 1912: art and culture where not formally inserted in the Olympic Games; b) from Stockholm (1912) to London (1948): Olympic Games editions with Olympic arts competitions; c) From Melbourne (1955) to Barcelona (1992): the distinct cultural programme conceptions. In the second part, the article investigates directly the Berlin Games (1936), from the assumption which the German government understood the "symbolic strength of cultural elements" and potentialized it with propaganda strategies to consolidate the main representations of the Nazi model.

KEYWoRDS: Cultural Programme; Olympic Games; Culture; Berlin Games. 
FuLiA / UFMG - O lugar da cultura nos Jogos Olímpicos

\section{INTRODUÇÃo}

Os Jogos Olímpicos são reconhecidos como o maior evento esportivo mundial da atualidade. ${ }^{1}$ Pensar em Jogos Olímpicos, à primeira vista, pode remeter exclusivamente ao mundo do esporte: atletas, competições, estádios, etc. Contudo, um olhar um pouco mais abrangente mostrará que estes não se restringem apenas ao campo esportivo, pois estabelecem um diálogo próximo com o campo das artes e da cultura desde a sua primeira edição na era moderna, em 1896.

No Brasil, poucas são as pesquisas e publicações que se propõem a abordar as relações entre programação cultural e Jogos Olímpicos; quando muito, percebem-se esforços voltados para a análise das cerimônias de abertura e encerramento das Olimpíadas e Paraolimpíadas, ${ }^{2}$ destacando, em geral, as representações de cultura e identidade nacionais mobilizadas e trabalhadas nessas ocasiões. Outro aspecto pouco abordado é o fato de que tais eventos, que incorporam 100 anos de programação cultural e artística, têm impactado, ao longo do tempo e de maneira variável, as cidades e países que os sediaram. ${ }^{3}$

É justamente sobre esse aspecto que este artigo pretende lançar luzes. 0 objetivo é refletir sobre como elementos do campo artístico e cultural se comportaram ao longo do tempo, apontando como essa variação é resultado de estratégias deliberadas de determinados atores, a partir de um contexto social específico. ${ }^{4}$ Parto da premissa de que os programas de cultura - competições

\footnotetext{
${ }^{1}$ Para justificar essa afirmação, a maior parte dos estudos utiliza como parâmetro a cobertura da mídia. Os Jogos Olímpicos e os Jogos Paralímpicos são, respectivamente, o primeiro e o terceiro maior evento do mundo, do ponto de vista de audiência televisiva e dos números de logística e produção.

${ }^{2}$ RUBIO. A imagem do Brasil nos Jogos Olímpicos do Rio de Janeiro; FREITAS et al. Estereótipos e Clichês: A (Re)Apresentação Do Brasil Na Cerimônia De Encerramento Da Olimpíada 2012.

${ }^{3}$ Para fins deste artigo, utilizei a noção de "Programação Cultural dos Jogos Olímpicos" como um conjunto de ações culturais que recebem a chancela dos organizadores dos jogos, se constituindo assim como um componente que representa uma seção das atividades olímpicas de caráter cultural ou artístico e que ocorrem antes elou durante a realização dos Jogos Olímpicos.

${ }^{4}$ Cabe registrar que, neste artigo, não serão utilizadas fontes primárias, a pesquisa e a análise se basearam em artigos e livros de autores que escreveram sobre o tema. Assim, trata-se de um passo importante para a pesquisa da tese de Doutorado, uma vez que se apresenta como um primeiro exercício de levantamento bibliográfico e de sistematização de leituras sobre e o objeto do trabalho.
} 
artísticas ou festivais - são um campo privilegiado para a consolidação dos aspectos simbólicos presentes nas edições dos Jogos Olímpicos.

Para dar conta dessa proposta, considerei importante sistematizar as informações em um breve panorama temporal, relativo à dimensão cultural dos Jogos Olímpicos, estruturado a partir de três momentos: ${ }^{5}$ a) De 1896 a 1912: as artes e a cultura não estavam formalmente inseridas nos Jogos Olímpicos; b) De Estocolmo (1912) a Londres (1948): edições de Jogos Olímpicos com competições das artes olímpicas; c) De Melbourne (1956) a Barcelona (1992): as diferentes concepções de programação cultural. ${ }^{6}$

A partir da pesquisa para a construção desse "panorama temporal", foi possível perceber especificidades nas diferentes programações culturais existentes nas edições dos Jogos Olímpicos, bastante ricas e ainda muito pouco exploradas nas pesquisas acadêmicas.

Para este artigo, optei por investigar mais detidamente os Jogos de Berlim (1936), em função de um consenso existente na literatura de que este foi um divisor de águas no que diz respeito ao valor dado pelos organizadores das Olimpíadas - ao que estou chamando de "dimensão cultural e artística". Assim, pretendo destacar ao longo do artigo, elementos que demonstrem que o governo nazista investiu fortemente em tal dimensão, a partir de uma percepção do potencial existente no campo simbólico e cultural, para o sucesso da construção de seus objetivos. ${ }^{7}$ Dito de outra forma, a hipótese aqui desenvolvida é de que o governo alemão entendeu a "força simbólica dos elementos culturais" e a potencializou com estratégias de propaganda para consolidar as principais representações do modelo nazista.

\footnotetext{
${ }^{5}$ Uma parte significativa da bibliografia sobre o tema usa esta divisão temporal como referência, uma vez que ela traduz a divisão dos diferentes "formatos dos programas culturais" - competições artísticas, festivais ou olimpíadas culturais - que foram implementados ao longo das edições de Jogos Olímpicos (GARCIA. 2010).

${ }^{6}$ Fiz uma opção pelo recorte temporal que compreende o período de 1896-1992. A decisão de não analisar as últimas edições dos jogos, deu-se em função de compreender que os Jogos de Barcelona (1992) inauguraram um novo modelo das chamadas "Olimpíadas Culturais", que marcaram os últimos 25 anos e que merecem uma investigação mais acurada, a qual este trabalho não se propõe.

7 É importante registrar que não estou fazendo nenhum juízo de valor sobre a qualidade - ou a contemporaneidade - da programação cultural. Não há dúvidas de que, do ponto de vista estético e conceitual, o governo alemão - e a programação cultural proposta - era conservadora, autoritária e elitista, no sentido de compreender o "campo artístico" a partir das linguagens tradicionais.
} 
FuLiA / UFMG - O lugar da cultura nos Jogos Olímpicos

\section{BREVE PANORAMA TEMPORAL RELATIVO À DIMENSÃO CULTURAL DOS JOGOS OLÍMPICOS (1896-1992)}

a) De 1896 a 1912: as artes e a cultura não estavam formalmente inseridas nos Jogos Olímpicos

Os primeiros registros que a literatura apresenta sobre a presença da cultura e das artes ${ }^{8}$ nos Jogos Olímpicos modernos datam de 1906. Quando o Barão Pierre de Coubertin defendeu a inclusão, nos Jogos Olímpicos, de um programa artístico para trazer um "cenário estético" para as competições esportivas ou, como observado por Gold e Revill, "para assumir o ethos do panegyris do festival clássico [grego] - uma assembleia festiva na qual as pessoas se uniram para participar de ritos religiosos, competições esportivas e performances artísticas". ${ }^{9}$

Para Pierre de Coubertin, o objetivo era reviver, não só as competições esportivas da Antiguidade, mas também a dimensão cultural e artística dos jogos originais, uma vez que os concursos esportivos e artísticos foram uma parte essencial do ritual religioso e cerimonial na Grécia Antiga. ${ }^{10}$

Nos Jogos da Antiguidade, atletas, filósofos, estudiosos, poetas, músicos, e escultores mostravam seus talentos, o que Coubertin chamou de "espírito de

\footnotetext{
${ }^{8}$ A maioria dos documentos do $\mathrm{COI}$ - e a literatura que trata do tema - utiliza os conceitos de cultura e arte como sinônimos, a partir da identificação do programa cultural olímpico com um festival de "artes". Só partir da edição de Barcelona (1992) é que a dimensão antropológica da cultura passou a ser considerada. Do ponto de vista acadêmico e institucional, é a partir da década de 1990 que se intensificam os estudos de políticas culturais que reconhecem a cultura a partir do conceito que foi aprovado na Conferência Mundial sobre Políticas Culturais, a cultura compreendida em seu sentido mais amplo, ou seja, considerada como o conjunto dos traços distintivos, espirituais e materiais, intelectuais e afetivos que caracterizam uma sociedade ou um grupo social. Dentro do campo da cultura temos, além das artes e das letras, os modos de vida, os direitos fundamentais do ser humano, os sistemas de valores, as tradições e as crenças (UNESCO. 1982).

${ }^{9}$ Os concursos esportivos e artísticos foram parte integrante do ritual religioso e cerimonial na Grécia clássica. O calendário do festival foi dominado por quatro ciclos regulares de Pan-Hellenic Jogos: Pythian Games, Isthmian Games, Nemean Games e Jogos Olímpicos. Os Jogos Olímpicos, realizados em Olympia, acerca de 90 milhas $(150 \mathrm{~km})$ a oeste de Atenas, homenageavam Zeus e surgiram como o mais importante desses jogos. Ver: GOLD; REVILL. Reviving the panegyrics, p. 2.

${ }^{10}$ Ainda segundo Coubertin, as competições não devem ser entre países, mas entre cidades; os atletas devem ser amadores; as mulheres não deveriam se envolver com as competições; os Jogos Olímpicos deveriam ser realizados de quatro em quatro anos; as guerras deveriam cessar para a realização do evento. Todas essas são facetas muito visíveis desta busca de conexão com a Grécia Antiga. Todas adequadas ao seu projeto para a modernidade. Trata-se de uma releitura moderna e eclética do período da Antiguidade. Ver: GOLD; REVILL. Reviving the panegyrics.
} 
olimpismo". Nesse sentido, para Coubertin, o olimpismo tinha como fundamento a integração do corpo, do intelecto e do espírito, vistos como manifestações de um homem harmonioso e educado. A proposta dele era criar um ambiente na sociedade moderna, em que artistas e atletas se inspirassem mutuamente.

Coubertin usou a palavra eurhythmy para descrever o casamento harmonioso do esporte e da cultura, atletismo e arte, músculo e mente. Ele acreditava que a fusão de arte e esporte estava no coração dos Jogos Clássicos e os Jogos Olímpicos modernos só teriam sucesso se conseguissem recuperar essa integração. Esse seria o grande desafio, uma vez que "as massas", como ele chamou o público, perderam todo o senso de eurhythmy e precisaria se reeducar para poder apreciar adequadamente a relação entre esporte, escultura, música e arquitetura. Só então seria possível reconhecer e experimentar a harmonia entre as dimensões do corpo e da alma, presentes em sua visão do Olimpismo. ${ }^{11}$

Nas quatro primeiras edições dos Jogos Modernos - Atenas 1896, Paris 1900, St Louis 1904 e Londres 1908 - a arte não foi incorporada formalmente ao programa olímpico, e as iniciativas dos organizadores restringiram-se a festividades que celebravam o evento. Em Atenas (1896), as autoridades decoraram as ruas e iluminaram a Acrópole; a celebração incluiu procissões de tochas, desfiles, fogos de artifício, um show da Orquestra Filarmônica de Atenas e a encenação de Antígona, de Sófocles. Houve banquetes e recepções para atletas, organizadores e membros do COI, culminando em um almoço dado pelo rei no salão do palácio. Nas três edições seguintes - 1900, 1904 e 1908 -, a estratégia para dar conta da dimensão artística foi buscar aproximação com as Feiras Internacionais. ${ }^{12}$

\footnotetext{
${ }_{11}^{11}$ GOLD; REVILL. Reviving the panegyrics.

${ }^{12}$ Cornelsen chama à atenção para o fato de que "[a] história dos Jogos Olímpicos na era moderna nos mostra que parte desse caráter sagrado da tradição olímpica na Grécia Antiga foi retomada pelo Barão de Coubertin e encontrou sua expressão numa série de procedimentos protocolares adotados pelo Comitê Olímpico Internacional (COI). Desde o início dos Jogos Olímpicos na era moderna, em 1896, o caráter cerimonial do evento foi de suma importância tanto para os representantes do $\mathrm{COI}$ quanto para os organizadores dos jogos. O destaque recaía principalmente sobre as cerimônias de abertura e de encerramento, bem como sobre a premiação dos atletas. $O$ desfile das delegações na abertura dos Jogos, presente no protocolo olímpico desde 1908 na Olimpíada de Londres, já simulava o espírito da ponte entre Grécia Antiga e o país-sede, na
} 
FuLiA / UFMG - O lugar da cultura nos Jogos Olímpicos

O Barão de Coubertin trabalhou em várias frentes para colocar em prática seu ideal de olimpismo e superar resistências existentes entre os membros do COI. Uma primeira vitória foi o fato de a Carta Olímpica13 estabelecer que "misturar o esporte com a cultura e a educação" seria fundamental para o princípio do olimpismo. ${ }^{14}$

Essa estratégia se fortaleceu em 1906, quando Coubertin convocou uma "Conferência Consultiva sobre Arte, Letras e Desporto" na Comédie-Française, em Paris. A conferência contou com intelectuais, artistas e especialistas desportivos que debateram sobre as possibilidades de integrar as artes aos Jogos Olímpicos modernos. “O texto do convite explicitava que o propósito da reunião era estudar até que ponto e de que forma as artes poderiam participar da celebração dos Jogos Olímpicos modernos e se integrar à prática de esportes, para o enriquecimento mútuo". ${ }^{15}$

Como resultado da conferência e para garantir a associação das artes com esportes, ficou definido que seria estabelecida uma competição artística que deveria ser parte de cada celebração dos Jogos Olímpicos. Essa competição foi chamada de "pentatlo das musas", e sua proposta era, tal qual no esporte, premiar os vencedores, ou seja, os melhores artistas nas seguintes categorias: escultura, pintura, música, literatura e arquitetura.

Para preparar o primeiro pentatlo de musas, foi criada uma comissão pelo Comitê Organizador Olímpico de Londres, cidade-sede dos jogos de 1908. Contudo, várias discordâncias no âmbito da comissão organizadora resultou no cancelamento

medida em que a delegação grega passou a abrir o desfile, por representar o berço dos Jogos Olímpicos, enquanto a delegação local fechava o desfile, como é o procedimento até hoje. Em 1920, na Antuérpia, introduziu-se o juramento olímpico, pronunciado por um atleta do país-sede dos jogos, revivendo assim, simbolicamente, o gesto dos helenos diante da estátua de Zeus em Olímpia. Em 1928, na cidade de Amsterdã, foi aceso pela primeira vez o fogo olímpico, que deveria ser mantido aceso em uma pira durante o período de realização dos jogos" (CORNELSEN. 2006, p. 211).

${ }_{13}$ Atualizada pela última vez em 2013, a Carta Olímpica é o conjunto de regras adotadas pelo COI para a organização dos jogos e para o comando do movimento olímpico. Em sua introdução, a carta delimita seus propósitos principais: estabelecer princípios e valores do olimpismo; servir como código do COI; definir direitos e obrigações dos três constituintes principais do movimento olímpico: o COI, as federações internacionais e os comitês olímpicos nacionais e o comitê organizador de cada edição dos jogos.

${ }_{14}$ GARCíA. The concept of olympic cultural programme, p. 2.

${ }^{15}$ GARCÍA. The concept of olympic cultural programme, p. 2. 
FuLiA / UFMG - O lugar da cultura nos Jogos Olímpicos

deste e a decisão de ter uma competição de artes olímpicas no bojo dos jogos esportivos só teve seu início efetivo nos Jogos de Estocolmo, em 1912.16

b) De Estocolmo (1912) a Londres (1948): edições de Jogos Olímpicos com competições das artes olímpicas

Os Jogos Olímpicos de Estocolmo (1912) são considerados como o momento inaugural de uma nova dinâmica onde o ideal de Coubertin poderia finalmente ser posto em prática. As competições artísticas passaram a ser organizadas em paralelo às competições esportivas. Assim, os artistas, como os atletas, passam a competir por medalhas.

Durante esse período em que a lógica de "competições artísticas" esteve em vigência, os regulamentos e os parâmetros do concurso mudaram bastante e isso significou uma variação grande no que poderíamos chamar de um modelo padrão de programação das competições. ${ }^{17}$ Hanna, em seu artigo, chama à atenção para grande quantidade de dificuldades apresentadas por parte dos organizadores para implementar as "competições artísticas".18

A primeira dificuldade apontada pelos organizadores, e que aparece nos relatórios do COI, era a inconstância nas competições de artes, dificultando o planejamento e gerando muita disputa entre os segmentos artísticos. As cinco áreas que compunham originalmente o pentatlo das musas não se mantiveram como únicas categorias de competição. Ao longo do tempo, foram criadas várias subcategorias que,

\footnotetext{
16 As competições artísticas foram incorporadas aos jogos de 1912, mas sua organização enfrentou dificuldades e resistências. A Real Academia das Artes da Suécia e as Sociedades Artísticas Suecas não simpatizavam com as competições e não quiseram colaborar em sua organização. As competições foram assumidas pelo COI na pessoa de Pierre de Coubertin que recebeu as inscrições e organizou o julgamento. Entre os vencedores da medalha de ouro estava o próprio Coubertin com uma "Ode to Sport", submetida sob o pseudônimo de Georges Hohrod e M. Esch. Ver: GOLD; REVILL. Reviving the panegyrics.

${ }^{17}$ Este artigo não se propõe a discutir detalhadamente a programação das competições artísticas e culturais de todas as edições dos jogos desse período. A proposta nesta parte do texto é fazer um breve balanço e tentar apresentar elementos que possibilitem o leitor a refletir sobre o período de 1912-1948, seja em relação aos elementos que aproximam as edições desse período - o caráter competitivo -, ou quanto aos elementos que o diferem - os regulamentos mudaram e isso significou várias alterações na estrutura das competições.

${ }^{18}$ HANNA. Reconciliation in Olympism.
} 
FuLiA / UFMG - O lugar da cultura nos Jogos Olímpicos

a cada edição, geravam muita controvérsia. ${ }^{19} \mathrm{Um}$ segundo aspecto que também gerou polêmica foi a determinação de que as temáticas das competições artísticas teriam que ser ligadas ao esporte. Um terceiro obstáculo, bastante citado na literatura, diz respeito à proibição da participação de artistas profissionais nas competições. ${ }^{20}$ Os debates sobre esse tema eram muito polêmicos, pois, além do fato dessa premissa "significar um possível prejuízo da qualidade das obras" e "diminuir o interesse do público", permanecia uma indefinição subjetiva, pois o COI reconheceu que todos os artistas eram profissionais em sua devoção. ${ }^{21}$

Outros aspectos de ordem logística e financeira foram determinantes para a decisão do COI em "cancelar as competições artísticas a partir de 1952". Após os Jogos de Londres de 1948, o Comitê Britânico de Belas Artes, que havia sido criado na ocasião dos jogos, compilaram um "relatório das sugestões para futuros concursos de artes”. Ele seria destinado a ser usado como guia para a organização e melhorias das futuras competições de artes. Segundo Garcia, as recomendações do relatório incluíram reduzir o número de categorias das competições artísticas. ${ }^{22}$

Em 1950, os problemas e as dificuldades observadas até então foram percebidos como muito maiores do que os benefícios e conquistas trazidos pelas competições olímpicas de arte. Havia um consenso que o público estava mais interessado nas competições esportivas do que nas de arte. Para rever a situação, um longo processo de discussão ocorreu dentro do COI. Como resultado desse processo controverso, foi decidido que, a partir de 1952, a presença das artes nas Olimpíadas assumiria a forma de exposições e festivais culturais em vez de competições.

\footnotetext{
${ }^{19}$ Referência a um documento do COI da 44론 Sessão do COI em Roma, citado por Hanna em Reconciliation in Olympism.

${ }^{20} \mathrm{O}$ debate sobre amadorismo, tão presente na área esportiva, também foi intenso na área cultural. Na concepção original dos Jogos Olímpicos, um critério chave para a inclusão como concorrente olímpico foi a necessidade de ser um atleta amador, isto é, não ser um profissional de tempo integral e competir no esporte para ganhos financeiros ou comerciais. Essa regra também foi aplicada ao concurso de artes e causou controvérsia à medida que se tornou um desafio para atrair obras de arte de alta qualidade, uma vez que os colaboradores não podiam ser artistas profissionais. Avery Brundage foi eleito presidente do COI em 1952 e foi fortemente contrário a qualquer forma de profissionalismo nos Jogos Olímpicos; suas opiniões prevaleceram durante a longa revisão do formato das competições de artes olímpicas e prioridades que ocorreram entre 1949 e 1952, e levou a sua substituição por exposições artísticas, a partir de então.

${ }^{21}$ HANNA. Reconciliation in Olympism.

${ }^{22}$ GARCÍA. The concept of olympic cultural programme.
} 
Como pretendo apresentar mais adiante, fica evidente que, com exceção dos Jogos de Berlim (1936) onde houve um investimento extraordinário - financeiro e institucional por parte do governo nazista -, em todas as demais edições de Jogos Olímpicos desse período de 1912 a 1952, a questão das competições artísticas, e/ou programação cultural, ocupava um lugar periférico na organização dos jogos.

c) De Melbourne 1956 a Barcelona 1992: as diferentes concepções de programação cultural

Com a decisão de cancelamento das competições artísticas por parte do COI, as cidades que sediaram os jogos, a partir de então, propuseram uma enorme variedade de formatos de programação cultural.Em uma breve caracterização temporal, Garcia explica que o primeiro Festival Oficial de artes olímpicas do pós-guerra foi realizado nos Jogos de Melbourne, em 1956. ${ }^{23}$ O festival teve dois componentes principais: um de artes visuais e literatura, e outro de música e drama. As "exposições e festivais" foram executadas no período dos jogos propriamente dito, com algumas atrações, iniciando nas semanas que antecederam a abertura oficial do evento. ${ }^{24} \mathrm{~A}$ Cidade do México, que sediou as Olimpíadas em 1968, apostou na estratégia de organizar uma programação começando um ano antes dos jogos e, pela primeira vez, a proposta foi apresentada formalmente ao COI com a denominação de "programa cultural". Moscou, em 1980, organizou um festival de 16 meses. Mas foi Barcelona, em 1992, que inaugurou uma verdadeira "Olimpíada Cultural", com duração de quatro anos, se tornando modelo para as futuras edições. Doravante, os dossiês de candidatura das cidades passaram a apresentar ambiciosos programas culturais, ressaltando a importância deles para a identidade e celebração dos jogos. ${ }^{25}$

\footnotetext{
${ }^{23}$ GARCÍA. The concept of olympic cultural programme.

${ }_{24}^{24}$ HANNA. Reconciliation in Olympism, p. 76.

25 Os Jogos de Barcelona (1992) foram pesquisados de maneira significativa. A maioria dos estudos ressalta seus aspectos positivos. Contudo, o texto de Moragas (2008) problematiza vários aspectos da agenda cultural proposta.
} 
FuLiA / UFMG - O lugar da cultura nos Jogos Olímpicos

Moragas ressalta que o programa foi inspirado no início de uma nova "ideologia” na programação cultural, que foi proposto como uma identidade distintiva para Barcelona: criativo, renovável, com poucas concessões à comercialização de arte, verdadeiramente cosmopolita, etc. ${ }^{26}$ Além disso, foram adicionados alguns objetivos de política cultural abrangentes, que posteriormente não foram cumpridos no período entre o início da Olimpíada e a cerimônia de encerramento dos jogos. Nesta perspectiva, a "Olimpíada” acabou por ser muito curta para atingir esses objetivos. Alguns foram alcançados anos mais tarde, enquanto outros ainda ficaram pendentes na agenda cultural catalã.

A natureza variável e a consistência de alguns programas culturais dos Jogos Olímpicos foram estudadas por Guevara, ${ }^{27}$ em sua análise comparativa do componente cultural nos Jogos Olímpicos do México, em 1968, para os de Barcelona, em 1992. Guevara aponta as diferenças existentes nos programas de cultura apresentados pelos comitês organizadores de cada edição das Olimpíadas, investigando seu perfil e buscando traçar aproximações e variações. Essas diferenças - ou variações - são contrastadas em termos de duração dos festivais e de sua estrutura de gestão.

Em relação à duração da programação cultural, houve uma variação de três semanas - Moscou (1980) - há quatro anos - Barcelona (1992). Algumas edições propuseram uma duração intermediária, como foi o caso do Festival de Artes do México em 1968 - um ano -, o festival de Roma em 1960 - seis meses - e de Los Angeles em 1984 - dez semanas. Cabe ressaltar que um novo desenvolvimento no conceito de programação cultural olímpica ocorreu na época dos Jogos de Barcelona (1992). O modelo proposto foi de uma Olimpíada Cultural, que previa um programa para celebrações culturais que durou os quatro anos que separaram os Jogos Olímpicos de Verão anteriores, em Seul (1988), até os de Barcelona, em 1992.28

\footnotetext{
${ }^{26}$ MORAGAS. The Cultural Olympiad of Barcelona in 1992.

${ }^{27}$ apud GARCIA. The concept of olympic cultural programme.

${ }^{28}$ Beatriz Garcia chama à atenção para o fato de como, só nas edições recentes dos jogos, particularmente os de Barcelona (1992) em diante, que as ambições do programa cultural olímpico passam a se aproximar de questões presentes no debate de políticas culturais contemporâneas,
} 
FuLiA / UFMG - O lugar da cultura nos Jogos Olímpicos

Em relação à governança da programação olímpica, também houve uma grande variedade de modelos: Guevara considera que houve: a) "gerenciamento central" quando o programa cultural foi de responsabilidade do comitê organizador, como foi o caso no México (1968), Munique (1972) e Seul (1988); b) "gerenciamento descentralizado" ou "gerenciamento compartilhado", ocorreu quando os eventos culturais foram de responsabilidade de parcerias entre os comitês organizadores e outras instituições, privadas ou públicas - um caso representativo foi Montreal (1976), no qual as províncias canadenses foram responsáveis pela concepção dos programas artísticos, enquanto o departamento cultural do comitê organizador era responsável pela logística; c) "gestão do Estado", ocorreu quando um ou vários órgãos públicos centralizavam o programa de cultura, assim se deu em Moscou (1980); d) "gestão privada" que caracterizou-se pela oposição à gestão estatal, o exemplo mais claro desse tipo foi Los Angeles (1984), quando o comitê organizador foi estabelecido como uma empresa privada e seu departamento cultural contratou agências para coproduzir o evento; e finalmente houve alguns casos de e) "gestão mista", ocorreu em Barcelona (1992), onde existiu uma organização especial para cuidar do programa cultural. A Olimpíada Cultural SA (OCSA) foi, ao mesmo tempo, separada e dependente do Comitê Organizador Olímpico (COOB); por um lado, teve um comitê composto por representantes da administração pública, independentes do comitê organizador; por outro lado, o Conselho de Administração da OCSA foi presidido pelo prefeito de Barcelona e presidente do СOOB. ${ }^{29}$

Em sua tese, Guevara discute de forma comparada outros aspectos que variaram nas edições dos jogos do período estudado: consistência e qualidade

tais como: diversidade, identidade, participação, etc. "Para além disso, os programas culturais também passam a buscar uma aproximação com as agendas econômicas e sociais das cidadessede e dos governos, combinando assim suas aspirações artísticas com outras dimensões, como a construção de identidade, atraindo o turismo e contribuindo para o desenvolvimento urbano" (GARCIA. 2012, p. 5). A maior parte dos programas culturais dos jogos foi operacionalizado, principalmente, como um programa de artes ou um festival de artes - cultura e arte eram sinônimos.

${ }^{29}$ apud GARCIA. The concept of olympic cultural programme. 
FuLiA / UFMG - O lugar da cultura nos Jogos Olímpicos

artísticas nacionais, ${ }^{30}$ melhoria dos serviços culturais existentes nas cidades, ${ }^{31}$ proposta de apresentação da diversidade cultural do país, ${ }^{32}$ estratégia de usar a programação cultural para viabilizar a projeção internacional, etc. ${ }^{33}$

Para refletir sobre as diversas formas assumidas pela programação cultural ao longo do tempo, é importante registrar que nunca houve por parte do COI - e nem consagrado na literatura já visitada - diretrizes detalhadas em documentos ou manuais sobre o papel, ou principais funções, que o programa cultural dos Jogos Olímpicos devem cumprir. ${ }^{34}$ Não há esclarecimentos prescritos sobre o que poderia ser incluído dentro de um programa oficial de cultura e sobre sua relação com várias outras áreas congêneres: cerimônias, educação, comunicação, etc. Contudo, a maioria dos programas de cultura usam como documento referência a Carta Olímpica,35 justificando suas propostas a partir de suas diretrizes gerais.

Os regulamentos e diretrizes existentes do COI enfatizam que para se tornar uma cidade anfitriã olímpica é obrigatório organizar e promover um programa cultural que atue paralelamente ao esporte. Atualmente esses regulamentos aparecem

${ }^{30}$ Munique e Los Angeles eram cidades que já faziam parte de importantes circuitos culturais e contavam com orçamento apropriado para apresentar um grande festival de importância internacional.

31 O melhor exemplo são os Jogos de Barcelona (1992); a iniciativa de apresentar uma programação cultural com duração de quatro anos foi fundamental para patrocinadores e parceiros investirem na melhoria dos equipamentos culturais existentes na cidade.

32 Segundo Guevara (1992 apud GARCIA, 2010), a "vitrine do folclore e da diversidade cultural" foi um fator fundamental no desenho do programa cultural México (1968), Montreal (1972) e Moscou (1980). Os três apresentaram eventos com um alto conteúdo nacional e folclórico.

${ }^{33}$ apud GARCIA. The concept of olympic cultural programme. O objetivo de obter uma projeção internacional foi especialmente alcançado em Seul (1988) e Barcelona (1992). Nas palavras de Guevara (1992 apud GARCIA, 2010), os jogos viabilizaram a oportunidade do reconhecimento mundial e, por isso, combinaram a expressão local com elementos internacionais.

${ }^{34}$ Para as demais áreas que o COI julga prioritárias para a "entrega dos jogos" - energia, instalações, segurança, transporte, cerimônias, etc. - há manuais detalhados, bem como orçamento mínimo garantido - por parte do COI e por parte dos governos através das cartas de garantia.

35 A Carta Olímpica é a codificação dos princípios fundamentais do olimpismo, regras e regulamentos adotadas pelo Comitê Olímpico Internacional (COI). Governa a atividade da organização e a intervenção do movimento olímpico e proporciona as condições para a celebração dos Jogos Olímpicos. Na sua essência, a Carta Olímpica serve três propósitos fundamentais: a) como instrumento de natureza constitucional, rege-se e apela aos princípios fundamentais e valores essenciais do olimpismo; b) constitui os estatutos para o Comité Olímpico Internacional; c) em adição aos pontos anteriores, define os principais direitos recíprocos e obrigações dos três principais constituintes do movimento olímpico, nomeadamente o $\mathrm{COI}$, as Federações Internacionais e os Comitês Olímpicos Nacionais, bem como os comitês organizadores de Jogos Olímpicos. Todos esses organismos são requeridos a agir em conformidade com a Carta Olímpica. 
FuLiA / UFMG - O lugar da cultura nos Jogos Olímpicos

na Carta Olímpica - Regra 44: Cultura Programa - e nas diretrizes oficiais para a candidatura da cidade anfitriã - Tema 13: Cultural Programa e Acampamento Juvenil. No entanto, nenhum desses regulamentos, diretrizes e recomendações parecem esclarecer qual é a função exata de um programa cultural para os jogos. ${ }^{36}$

Garcia chama à atenção para o fato de "que a falta de uma definição concreta permitiu uma grande liberdade de ação e interpretação e contribuiu para gerar propostas culturais muito diversas por parte das candidaturas ao longo dos anos". ${ }^{37}$ Essa liberdade tem aspectos positivos, em função da autonomia e da não interferência do COI, mas também tem sido fonte de descontinuidades notáveis no compromisso do COI com a área da cultura, especialmente no que diz respeito à garantia de recursos para a área cultural.

Grande parte dos programas culturais olímpicos tiveram dificuldade para sustentar suas atividades - competições, festivais e programas -, em função da falta de prioridade da questão cultural na agenda dos Jogos Olímpicos. ${ }^{38}$ Por isso, os melhores exemplos de "sucesso" de implementação da dimensão cultural nos jogos, até 1992, são aqueles cujos governos compreenderam o caráter estratégico da cultura para implementar seus objetivos, como foi o caso de jogos de 1992 em Barcelona, na sua estratégia da parceria cultura-turismo, e Berlim em 1936, com a sua apropriação dos ideais da Grécia Antiga para justificar o programa nazista.

${ }^{36}$ Regra 44: Programa Cultural: o Comité Organizador dos Jogos Olímpicos (COJO) deve organizar um programa de eventos culturais que deverá ser submetido à Junta Executiva do COI para sua aprovação prévia. Este programa deve servir para promover relações harmoniosas, compreensão mútua e amizade entre os participantes e outros participantes dos Jogos Olímpicos. O Estatuto da Regra 44: o Programa Cultural deve incluir: a) eventos culturais organizados na vila olímpica e simbolizando a universalidade e a diversidade de cultura humana; b) outros eventos com a mesma finalidade realizada principalmente na cidade-sede, com um certo número de lugares sendo reservado gratuitamente para os participantes credenciados pelo $\mathrm{COI}$; c) o Programa Cultural deve abranger pelo menos todo o período durante o qual a vila olímpica está aberta. Fonte: Cartas de Garantia COI, 2007.

${ }_{38}^{37}$ GARCIA. The role Arts and Culture in the Olympic Games, p. 2.

38 Para Garcia (2012), do ponto de vista do COI, embora o movimento olímpico tenha como objetivo ser um projeto humanista abrangendo "esporte, cultura e educação" (COI, 1999, p. 8), a realidade dos Jogos Olímpicos é outra, onde há uma predominância total de questões esportivas em detrimento ao resto. 
FuLiA / UFMG - O lugar da cultura nos Jogos Olímpicos

Jogos Olímpicos de Berlim (1936): O CAMPO ARTíSTICo E CULTURAL COMO DimenSõES DETERMINANTES PARA A CONSTRUÇÃO SIMBÓLICA DO GOVERNO NAZISTA

Nesta seção do artigo, pretendo analisar mais detidamente os Jogos de Berlim (1936), partindo da premissa de que eles foram paradigmáticos no que diz respeito à valorização da dimensão cultural em Jogos Olímpicos, que prevalecia até aquele momento.

Proponho uma reflexão sobre a opção deliberada por parte do governo nazista em investir fortemente na dimensão cultural e artística dos jogos, a partir de uma percepção do potencial que tais elementos poderiam trazer para o sucesso da construção de seus objetivos. Nesse sentido, é possível afirmar que os jogos nazistas inauguraram uma percepção de cultura nos Jogos Olímpicos de 1936 que foi muito além de organizar "competições artísticas ou festivais", os quais eram tratados pelo COI como algo que as cidades-sede deveriam fazer para realizar "o desejo de Coubertin" e demonstrar o caráter humanístico dos Jogos Olímpicos. Eles colocaram em prática um programa de cultura que apostava fortemente no campo do simbólico e sua relação com os jogos da Antiguidade Grega.

As Olimpíadas de Berlim (1936) apresentaram uma série de inovações na sua programação cultural e artística numa escala completamente inédita que se tornaram paradigma de organização para o COI. ${ }^{39}$ Toda a programação estava alicerçada na busca de uma identificação com a Grécia Antiga. A estratégia usada pelo governo nazista para dar sentido e coerência ao discurso foi recorrer à Antiguidade grega, buscando “a construção de uma 'ponte' entre a Hélade e o Terceiro Reich, a partir da interpretação que os nazistas davam aos testemunhos culturais e artísticos gregos enquanto fenômenos históricos". 40

\footnotetext{
39 A programação cultural é muito extensa e este texto não se propõe a fazer uma análise detalhada, e sim pensar os seus impactos na construção simbólica dos Jogos de Berlim (1936). Para uma investigação profunda da programação, sugiro a leitura da revista: "Cultural views of the olympics" (2016).

${ }^{40}$ CORNELSEN. Olímpia a serviço de Germânia, p. 197.
} 
FuLiA / UFMG - O lugar da cultura nos Jogos Olímpicos

Cornelsen chama à atenção para a necessidade de perceber tais relações dentro de seu contexto histórico:

[...] É preciso localizá-lo dentro do contexto histórico em que está inserido: o período do Terceiro Reich ou, mais precisamente, o período de consolidação da política nazista, desenvolvida desde a ascensão de Hitler ao poder em 30 de janeiro de 1933. A apropriação indébita do teor cultural e artístico da Antiguidade grega como forma de legitimação político-ideológica foi um dos expedientes postos em prática pela cúpula nazista. Mais do que um fenômeno estético atemporal, tal apropriação fundamenta-se numa tentativa de atualização de valores e símbolos da Antiguidade atrelando-se, assim, a uma tradição de arte e cultura elevadas como representação de um momento singular na história da civilização ocidental. ${ }^{41}$

Segundo o autor, "desde as olimpíadas da era moderna [...] nunca o ideal olímpico foi tão deturpado e abusado até as últimas consequências". ${ }^{42}$

A eficácia da construção narrativa dos nazistas dependia fortemente de uma intensa estratégia publicitária, ${ }^{43}$ bem como de uma rotina permanente de relação com a imprensa:

Deve-se considerar também a questão da pré-censura de imprensa na Alemanha durante o regime nazista, num procedimento não comumente encontrado em Estados autoritários ou totalitários, quando um censor está presente nas redações de jornais, lê e suprime das matérias passagens indesejáveis, antes que essas sejam publicadas. Ao contrário, cada jornal ou revista devia enviar um redator às reuniões diárias no Ministério de Propaganda e Instrução Popular, em Berlim, nas quais "Instruções de imprensa" (Presseanweisungen) eram expedidas no sentido de indicar, previamente, que temas poderiam ser tratados ou suprimidos. Tais instruções variavam, basicamente, entre si sob dois aspectos: enquanto umas continham informações falsas a serem veiculadas através da imprensa, outras proibiam a divulgação de determinadas notícias. ${ }^{44}$

\footnotetext{
${ }^{41}$ CORNELSEN. Olímpia a serviço de Germânia, p. 199.

${ }^{42}$ CORNELSEN. Esporte e discurso totalitário, p. 319-320.

${ }^{43} \mathrm{O}$ Comitê e o Programa de Cultura/Artes de Berlim foi presidido por um representante do ministério da propaganda do Reich. Debora Good aponta o grande investimento de divulgação da programação artística no rádio e na imprensa. Segundo a autora, "havia um histórico desinteresse do público por esses assuntos e, neste caso, o programa de arte olímpica foi usado como uma ferramenta de propaganda para os nacional-socialistas alemães" (GOOD. 1999, p. 19).

${ }^{44}$ CORNELSEN. Os Jogos Olímpicos de Berlim 1936 e Rio2016, e os fantasmas do passado, p. 10.
} 
Vários outros autores que estudam o tema concordam com o caráter monumental dos Jogos de Berlim (1936), a maioria deles ressaltando a força manipuladora em um megaevento esportivo. Para Melo,

[...] a organização dos jogos, em vários sentidos tem relação direta com ascensão do nazismo no cenário alemão. Até Hitler chegar ao poder houve muitas dificuldades para o Comitê Alemão, no cenário de crise econômica em que estava imersa a República de Weimar. Com os nazistas no poder, o fuher [sic] determinou o investimento de grandes quantias e acompanhou pessoalmente a preparação do evento, o encarando como uma possível forma de propaganda do novo regime $[\ldots] .{ }^{45}$

Segundo Sigoli e de Rose,

[...] a ideia de nação poderosa constituída por cidadãos fortes e saudáveis fez com que os estados totalitários utilizassem o esporte como veículo publicitário de seus regimes políticos, fato ocorrido nos Jogos Olímpicos de Berlim, em 1936, que foram usados como propaganda do Estado nazista alemão, servindo para unir os alemães em torno do sentimento ultranacionalista do nazismo, divulgando também a suposta superioridade da raça Ariana, ideais estas de Adolf Hitler. ${ }^{46}$

A proposta que trago aqui é ir um pouco além do olhar meramente esportivo e apontar a potência que a dimensão cultural e simbólica assumem nesses megaeventos, especialmente quando existe uma estratégia de propaganda articulada, como foi o caso dos jogos de 1936.

A apropriação do universo da Grécia Antiga para a construção de uma imagem positiva na Alemanha nazista pode ser observada a partir de diversos elementos. Cito aqui alguns deles: a) estratégia dos nazistas de sacralizar aspectos que eram indissolúveis da Grécia Antiga: esporte, arte e religião; b) o uso da "imagem da trégua olímpica" para blindar a representação belicista presente na imagem da Alemanha; c) os jogos de 1936 forjando uma mensagem de paz entre os povos, de superioridade ariana e de superioridade cultural por parte dos anfitriões; d) a comparação dos heróis gregos com os atletas alemães para comprovar a superioridade ariana e

\footnotetext{
${ }^{45}$ MELO. De Olímpia (776 a.C.) a Atenas (1896) a Atenas (2004): problematizando a presença da Antiguidade Clássica nos discursos contemporâneos sobre o esporte, p. 362.

${ }^{46}$ SIGOLI; DE ROSE JR. A história do uso político do esporte, p. 112.
} 
FuLiA / UFMG - O lugar da cultura nos Jogos Olímpicos

associação simbólica entre os atletas e os guerreiros; d) a "maquiagem" do Estado nazista para encobrir o antissemitismo do Estado no contexto olímpico; e) o culto ao corpo, associado ao pensamento racista e expansionista; f) o protagonismo do Ministério da Propaganda Nazista nas principais mensagens que o nazismo buscava apresentar ao mundo; ${ }^{47}$ g) o debate estético entre a arte romântica e a arte degenerada, etc. 48

\section{OLYMPIA: UM PRODUTO CULTURAL OLÍMPICO A SERVIÇO DO GOVERNO NAZISTA}

Vários desses elementos de "apropriação da Grécia Antiga” elencados acima vêm sendo estudados nos últimos anos pela literatura e aparecem de alguma forma no filme Olympia, de Leny Riefenstahl. Nesse sentido, é interessante pensarmos nele como "um produto cultural" que está ancorado em determinadas condições de produção e veiculação. Ele é, portanto, "produto" e "produtor" de determinantes históricos e sociais e não é casual que seja o registro oficial dos jogos de 1936.

Segundo Melo, "Olympia pode ser considerada uma das iniciativas pioneiras do diálogo dos Jogos Olímpicos com o que na época era o mais típico produto da sociedade de massas: o cinema, uma manifestação cultural da modernidade". ${ }^{49}$

O filme foi escrito, produzido e montado por Leni Riefenstahl, entre 1936 e 1938. A grandiosidade da obra e seu ineditismo ficam evidentes quando analisamos os números excepcionais para uma produção na década de 1930. A cineasta transformou o Estádio Olympia em um gigantesco estúdio cinematográfico, com orçamento inédito para esse tipo de linguagem: três milhões de marcos. "Foram utilizadas de 40 a 60

\footnotetext{
${ }^{47}$ Os jogos foram divulgados pelas primeiras programações transmitidas pela TV em caráter experimental: telões foram postos em vários pontos da Alemanha e cerca de 100 mil pessoas puderam ver os jogos ao vivo, gratuitamente (NAZARIO. 2012).

${ }_{48}$ Cornelsen afirma que "Hitler empresta à produção artística, sob o jugo nazista, um sentido idealizado de beleza e harmonia presente em manifestações artísticas da Antiguidade grega e opõe ao tipo do atleta olímpico as representações do corpo humano nas manifestações artísticas de vanguarda, sobretudo do expressionismo, onde prevalecia a estética do feio e do dissonante" (CORNELSEN. 2006, p. 214).

${ }^{49}$ MELO. De Olímpia (776 a.C.) a Atenas (1896) a Atenas (2004): problematizando a presença da Antiguidade Clássica nos discursos contemporâneos sobre o esporte, p. 364.
} 
câmeras de diversos formatos e filmadas todas as 129 modalidades. No total, foram gerados 400 quilômetros de negativos e 250 horas de projeção".50 0 filme, em sua versão final, ficou com 4 horas de duração, dividido em duas partes: Fest der Völker Parte 1, Festa dos Povos - e Fest der Schönheit - Parte 2, Festa da Beleza. Se o debate sobre a vanguarda estética e seu impacto cinematográfico é algo que ainda gera polêmica entre os especialistas, há um consenso de que Olympia "foi um marco do amadurecimento da estética hitlerista. Depois de dirigi-lo a cineasta Leny Riefenstahl jamais conseguiu se desligar das acusações de promover o nazismo".51

Luiz Nazário afirma que

[o]s Jogos Olímpicos de 1936 em Berlim politizaram o esporte como nunca antes, transformando os 4069 atletas dos 49 países participantes em peças manipuladas da gigantesca máquina de propaganda, para o orgulho da triunfante Alemanha sob o regime nazista, cujos valores eternos foram sublimados com extraordinário sucesso em Olympia (1938), de Leni Riefenstahl.52

Ao longo do seu artigo, o autor faz várias afirmações para reforçar sua tese de manipulação:

Durante os campeonatos, Hitler, Goebbels e Goering são mostrados como torcedores fanáticos que não escondem sua satisfação em ver triunfar os atletas da Alemanha, nem a decepção que sentem quando eles são derrotados. [...] Olympia pretensamente congraçava os povos numa festiva competição. Mas esse congraçamento e essa festa era uma farsa. Só alemães "arianos" poderiam participar de seus Jogos, já que desde 1933 as associações esportivas da Alemanha excluíam os atletas judeus e ciganos. ${ }^{53}$

Não pretendo iniciar um debate sobre a importância estética de Olympia, mas retomar a reflexão sobre em que medida o filme, como um produto cultural, colabora para colocar o ideal olímpico - e o sentido antigo do caráter sagrado dos jogos - a serviço da política e da ideologia. Nesse sentido, não é por acaso que o filme valoriza elementos ritualísticos e comemorativos que podem ser enquadrados no campo cultural, como é caso da cerimônia de abertura e do revezamento da tocha.

\footnotetext{
${ }^{50}$ NAZARIO. O discurso ideológico de Olympia, p. 139.

${ }^{51}$ MELO. Jogos Olímpicos e arte: Olympia, p. 53.

${ }^{52}$ NAZARIO. O discurso ideológico de Olympia, p. 134.

${ }^{53}$ NAZARIO. O discurso ideológico de Olympia, p. 140.
} 
Na cerimônia de abertura foi encenada, no anfiteatro Dietrich-Eckart, a peça Olympische Jugend - Juventude Olímpica -, de autoria de Carl Diem, e musicada pelos compositores Werner Egk e Carl Orff. O revezamento da tocha também ganha destaque em Olympia. 0 filme acompanhou o "fogo sagrado", que foi aceso em 20 de julho de 1936 na cidade de Olímpia (Grécia), e registrou a chama percorrendo sete países nas mãos de mais de 3.000 corredores, inaugurando assim um protocolo que passou a integrar o conjunto de cerimônias exigidas pelo COI.

Todavia, sem qualquer sombra de dúvida, dentre os vários aspectos que dão testemunho da construção propagandística e ideológica de uma "ponte" entre Olímpia e Germânia, a realização, pela primeira vez na história dos jogos, da corrida de revezamento da tocha olímpica, significou o ápice na representação de uma simbologia essa natureza. ${ }^{54}$

Por fim, ainda cabe registrar que o filme foi o coroamento do que o COI proclamou como um sucesso de organização dos jogos. Nesse sentido, é possível afirmar que os Jogos Olímpicos de Berlim (1936) extrapolaram os elementos tradicionais de um megaevento esportivo e se apropriaram do discurso do olimpismo de Coubertin para colocar em prática um programa cultural robusto. Foi com base na "força simbólica dos elementos culturais", aliada a uma estratégia de propaganda eficiente, que esse evento colaborou de forma decisiva para a consolidação de uma imagem que os nazistas pretendiam apresentar ao mundo: uma Alemanha onde os mais fortes triunfam sobre os mais fracos - superioridade ariana; de edificações monumentais - arquitetura -, de identificação entre atletas, soldados e deuses; enfim, de uma sociedade que deveria ser modelo para o mundo inteiro.

\section{CONSIDERAÇõES FINAIS: CULTURA E CONTEMPORANEIDADE NOS JOGOS OLÍMPICOS}

Pensar os Jogos de Berlim (1936) unicamente como uma peça publicitária, parece-me um olhar simplificador.

${ }^{54}$ CORNELSEN. Olímpia a serviço de Germânia, p. 215. 
Muito se falou e ainda se fala sobre a intensa propaganda utilizada naqueles jogos, sem, entretanto, considerar que, por mais eficaz que sejam as estratégias de propaganda, estas têm seus efeitos limitados, caso não haja um substrato simbólico que a sustente e que desfrute de valoração positiva marcada por discursos edificantes.

Para Cornelsen, o que garantiu ao projeto nazista eficácia em termos de propaganda foi poder contar com um mercado simbólico, explorando-o à exaustão. 0 sucesso seria, então, uma consequência do que ele chama de "estratégias de marketing político". 55

Eu arriscaria acrescentar que esse marketing político dialogou diretamente com elementos do programa cultural. Uma vez que as atividades artísticas e culturais realizadas naquela conjuntura ultrapassaram a mera condição de produto/mercadoria e se constituíram, portanto, como "produtos culturais" - inclusive o filme Olympia -, porque afetaram o campo das ideias, da expressão e, sobretudo, geraram significados.

0 andamento da minha pesquisa sobre o tema vai consolidando uma convicção de que a "centralidade da cultura" é uma escolha política, inclusive. Portanto, analisar ou refletir sobre programas culturais olímpicos requer um olhar mais atento para esses diálogos entre cultura e: economia, marketing, turismo, identidade, comunicação, desenvolvimento social e tantas outras esferas. Não cabe mais uma simplificação de entendimento de cultura como uma ação voltada para o investimento nas belas artes e restrita à manutenção de espaços culturais. ${ }^{56}$

Finalizo com uma provocação para as pesquisas acadêmicas sobre o tema: a atual posição privilegiada das Olimpíadas, como um fenômeno da mídia global, demanda uma reflexão permanente sobre o lugar que a cultura ocupa - e ocupou nos debates sobre planejamento, organização e realização dos Jogos Olímpicos. Essa

\footnotetext{
${ }^{55}$ CORNELSEN. Os Jogos Olímpicos de Berlim 1936 e Rio2016, e os fantasmas do passado, p. 1. ${ }^{56}$ A reflexão sobre políticas públicas destinadas ao campo da cultura também deve acompanhar essa ampliação de escopo e conceito. Afinal, é crescente essa espécie de "interação" da cultura para outras esferas - social e econômica -, o que tem resultado em uma (re)centralização da cultura como fonte importante para o estudo desenvolvido nas ciências sociais. Tal percepção é partilhada por Raymond Williams (1958) e Edward Thompson (1963), por exemplo. A base de fundação dos Estudos Culturais revela reflexões importantes nas relações entre cultura, história e sociedade, reforçando a percepção de cultura como "categoria-chave" para a investigação social.
} 
provocação só faz sentido se compreendermos "cultura" como um campo que vai além das ações voltadas para o fomento e a produção de atividades com foco nas "belas artes", ou seja, estou falando desses novos lugares que a cultura ocupa na conjuntura contemporânea, tanto na agenda da sociedade quanto na governamental. Em contextos de mundialização e globalização, é primordial perceber que a cultura deixa de ser apenas o alicerce e o ambiente de geração de sentido, de pertencimento, de teias simbólicas. Há também a exacerbação da característica econômica que se apoia em objetos culturais para mercantilizar "significados".

Investigar historicamente esse processo poderá contribuir para percebermos que a cultura não é apenas um valor agregado para os jogos, percepção que até os dias atuais prevalece no COI e na maior parte dos comitês organizadores. A depender da abordagem apresentada e da prioridade política, ela pode vir a ser o seu valor central.

\section{REFERÊNCIAS BIBLIOGRÁFICAS}

CORNELSEN, Elcio. Esporte e discurso totalitário: os Jogos Olímpicos de Berlim e o discurso nazista na imprensa. In: MARI, Hugo; MACHADO, Ida Lucia; MELLO, Renato de (org.). Análise do Discurso em perspectivas. Belo Horizonte: FALE/UFMG, 2002, p. 315-350.

CORNELSEN, Elcio. Olímpia a serviço de Germânia: a recepção da arte e da tradição olímpica da Grécia antiga no contexto dos Jogos Olímpicos de Berlim. Clássica (Brasil), 19.2, p. 196-223, 2006.

CORNELSEN, Elcio. Os Jogos Olímpicos de Berlim 1936 e Rio2016, e os fantasmas do passado. (no prelo).

FREITAS, Ricardo. et al. Estereótipos e clichês: a (re)apresentação do Brasil na Cerimônia de Encerramento da Olimpíada 2012. Animus, Revista Interamericana de Interação Midiática, v. 13, n. 25, 2014.

GARCíA, Beatriz. The concept of olympic cultural programme: origin, evolution and projection [online article]. International Chair in Olympism (IOCUAB). Barcelona: Centre d'Estudis Olímpics (CEO-UAB). 2010. Disponível em https://bit.ly/2KrQphe. Acesso em 10 out. 2017. 
GARCÍA, Beatriz. The role of arts and culture in the Olympic Games: from olympic arts competitions to Cultural Olympiads. 2012. Disponível em https://bit.ly/2rMiaKs. Acesso em 20 out. 2017.

GOLD, Maggie; REVILL, George. Reviving the panegyrics: cities and the staging of the Olympic arts and cultural festivals, 1896 to 2000. 2007. Disponível em https://bit.ly/2L6NQSW. Acesso em 15 out. 2017.

GOOD, Debora. The cultural Olympiad. In: CASHMAN, Richard; HUGHES, Anthony. (org.). Staging the Olympics: the event and its impact. Sydney: University of New South Wales Press, 1999, p. 159-69.

GUEVARA, Teresa. Análisis comparativo del programa cultural olímpico desde México'68 hasta Barcelona'92, como base para su realización en Puerto Rico'2004. Barcelona: Centre d'Estudis Olímpics i de l'Esport, 1992.

HALL, Stuart. A centralidade da cultura: notas sobre as revoluções culturais do nosso tempo. Educação \& Realidade, Porto Alegre, v. 22, n. 2, p. 15-46, jul.-dez. 1997.

HANNA, Michelle. Reconciliation in Olympism: the Sydney 2000 Olympic Games and Australia's indigenous people. Sydney: Walla Walla Press, University of New South Wales, 1999.

MELO, Victor. Jogos Olímpicos e arte: 'Olympia'. In: MELO, Victor Andrade de; PERES, Fabio de Faria (org.). O esporte vai ao cinema. Rio de Janeiro: Ed. SENAC Nacional, 2005.

MELO, Victor. De Olímpia (776 a.C.) a Atenas (1896) a Atenas (2004): problematizando a presença da Antiguidade Clássica nos discursos contemporâneos sobre o esporte. Phoenix, Rio de Janeiro, 13, p. 350-376, 2007.

MORAGAS, Miguel. The Cultural Olympiad of Barcelona in 1992: Good Points and Bad Points. Lessons for the Future [online article]. Barcelona: Centre d'Estudis Olímpics UAB. 2008. Disponível em https://bit.ly/2IHJFP1. Acesso em 20 out. 2017.

NAZARIO, Luiz. O discurso ideológico de Olympia. Aletria, Belo Horizonte, v. 2, p. 137-149, maio-ago. 2012.

RUBIM, Albino. Políticas Culturais no Brasil: desafios contemporâneos. In: CALABRE, Lia (org). Políticas Culturais: olhares e contextos. Rio de Janeiro: Fundação Casa de Rui Barbosa; São Paulo: Itaú Cultural, 2015.

RUBIO, Katia. A imagem do Brasil nos Jogos Olímpicos do Rio de Janeiro. Revista USP, São Paulo, n. 110, p. 66-71, jul.-ago.set. 2016.

SEMENSATO, Clarissa. Políticas públicas de cultura para os megaeventos no Rio de Janeiro. Seminário Internacional de Políticas Culturais. FCRB, Rio de Janeiro, 2012. 
SIGOLI, Mario Andre; DE ROSE JR, Dante. A história do uso político do esporte. R. Bras Ciência e Movimento. v. 12, n. 2, p. 111-117, 2004.

SUBIRÓS, Josep. The Cultural Olympiad: objectives, programme and development. In: GUEVARA, Michelle Ladrón de; BARDAJIÍ, M. (org.). Media and cultural exchanges: the experience of the last four summer Olympic Games. Barcelona: Centre d'Estudis Olímpics i de l'Esport, 1991, p. 84-86.

UNESCO. Declaração do México sobre políticas culturais. 1982. Disponível em https://bit.ly/2xXaZ6b. Acesso em 01 nov. 2017.

YÚDICE, George. A conveniência da cultura: usos da cultura na era global. Belo Horizonte: Editora UFMG, 2006. 